Journal of Mathematics and Informatics

Vol. 14, 2018, 53-61

ISSN: 2349-0632 (P), 2349-0640 (online)

Published 19 September 2018

www.researchmathsci.org

DOI: http://dx.doi.org/10.22457/jmi.v14a7

Journal of

Mathematics and

Informatics

\title{
Research on User's Interaction Participation in Virtual Communities Based on the Information Ecology Theory
}

\section{Yi Peng ${ }^{1}$ and Yu-jie $\mathrm{Li}^{2}$}

${ }^{1}$ School of Economics and Management

Chongqing University of Posts and Telecommunications

Chongqing-400065, Chongqing, China. E-mail: 635644882@qq.com

${ }^{2}$ Business School, China Research Institute of Enterprise Governed by Law

Southwest University of Political Science and Law,

Chongqing - 401120, Chongqing, China. E-mail: liyujie728@163.com

${ }^{2}$ Corresponding author

Received 18 August 2018; accepted 18 September 2018

Abstract. Based on the theory of information ecology, this paper explores factors that influence users' interaction participation behavior in virtual communities. It combines three core elements in information ecology: information, information man, and information environment. Using data collected from 401 users in virtual communities to conduct a hypothesis testing, the empirical results show that usefulness, trust and security have direct positive impact on interaction participation.

Keywords: interaction participation; virtual communities; information ecology theory; empirical study

\section{AMS Mathematics Subject Classification (2010): 62P25}

\section{Introduction}

With the advance of information technology, virtual communities have become important places in this information ecology. Nowadays, different types of virtual communities appear in our networks, such as interest-specific, relationship, entertainment, and commerce communities, among many others. Virtual communities, as indispensable platforms for information flowing and sharing, have enhanced the social contact of users [4], and realized users' self-efficacy [8].

Interaction participation can be understood as comprising of two parts"interaction" and "participation." Interaction means "being in contact" with two or more partners regardless of the activities that attract them together [19]. Community members interact on a regular basis online; they have exchanges in order to form a mutual relationship [19]. Participation means that volunteers and members may share no prior organizational affiliation [19]. It is shown in aspects like users being integrated in organizations and activities, their frequent involvement in assessments, and their conduction into user communications, among others. Participation in communities has been regarded as a measurement of the community's gain because it displays member satisfaction, while, simultaneously promoting important community goals [25]. 


\section{Yi Peng and Yu-jie Li}

Interaction participation is one of the users' most important behaviors in virtual communities in their mutual promotion and action. In the human-centered virtual communities, users' interaction participation allows users to meet their needs and realize their values; it forms the core of virtual communities as well. However, influencing factors of interaction participation need further exploration. Therefore, this paper is of important theoretical and practical significance.

Previous studies have researched interaction participation from different perspectives. Mai and Olsen investigated how personal values and personality jointly influence consumers' attitudes and behaviors towards their participation in virtual communities [15]; Shen et al. investigated virtual community loyalty from the perspective of interpersonal interaction among group members, treating interpersonal attraction and influence as antecedents to loyalty [20]; Yang et al. distinguished active and passive social interactions in the learning community with a conceptual framework [26]; Yoo et al. explored the factors that enhance member participation in business-tocustomer virtual communities [25]; Zhao et al., from the perspective of social capital, elaborated factors for the development of the virtual communication members' sense of belonging [27].

Most studies focus on users' interaction participation in virtual communities without considering three core elements: information, user, environment. However, for interaction participation behaviors, information is the object, the user is the subject, and environment is the place. These three elements have important influence on interaction participation, making it necessary to study them together. Unlike extant literature, our research 1) considers the virtual community a situation, thereby providing a clear explanation of users' interaction participation; 2) discusses factors influencing user's interaction participation in the virtual community using three elements-information, information man, and information environment-based on the information ecology theory; and 3) establishes a research model from the perspective of information ecology and conducts an empirical test.

\section{Background}

Nardi and O'Day defined information ecology as a system composed of people, practices, values, and technology in a certain environment [17]. They discussed the relationship between IT and human beings in this environment, noting that the human activity served by technology is more important than the technology itself. Other scholars claim that information is the sum of ecological factors and their relationship to each other within a certain range of information resources [5]; the sum of the relationship between information, people, and the environment [2]; and an integrity formed by the process of communication and circulation of information between people, organizations, and communities in a certain space [11]. As per the systematic perspective, the information ecosystem is composed of information, information man, and information environmentkey elements that create the ecosystem [22]. Information is an object of ecology [12], including information content and information resources; information man is a subject [12], that utilizes and controls information ecology; and the information environment is not only an ecological background and place, but also the sum of all external factors related to the information [12]. This paper argues that, under the information ecology theory, information, information man, and information environment are correlated and 


\section{Research on User's Interaction Participation in Virtual Communities Based on the Information Ecology Theory}

balanced. On one hand, information environment affects and restricts the information man; it plays an important role in their activities and the development of their relation. On the other hand, the information man's emotions and cognitions of information are critical to its quality and value.

This paper argues that, under the information ecology theory, information, information man, and information environment are correlated and balanced. On one hand, information environment affects and restricts the information man; it plays an important role in their activities and the development of their relation. On the other hand, the information man's emotions and cognitions of information are critical to its quality and value.

\section{Hypotheses}

From the perspective of information ecology, interaction participation is influenced by information, information man, and information environment. This paper argues that the most important factor of information is usefulness, the most important factor of information man is trust, and the most important factor of information environment is security.

\subsection{Information}

From the angle of information elements, this paper emphasizes the usefulness of information. This usefulness means the integrity and accuracy of information that can be exploited by users toward producing good results. The usefulness, reflecting the value of information [23], is a primary factor to attract and retain users. Useful information can allow users to perceive the value of information and more willingly exchange information in order to improve the frequency and intensity of their interaction participation. Therefore, this paper puts forward the following hypothesis:

H1: The usefulness has a positive effect on interaction participation.

\subsection{Information man}

Information man in this paper refers to users in virtual communities. From the angle of information man, trust among information men is emphasized. Trust, reflecting users' comprehensive evaluation to another user's behavior and ability, can usually be regarded as a decision-support tool. It is used for the analysis of relevantly reliable information sources, especially from a reliable source to seek advices and make decisions [16,28]. In a virtual community centered on people, behaviors and activities of users are built on the basis of trust. The higher degree of trust there is between users, the more willing they are to community activities, like commenting, sharing information, joining in interest groups. This then further strengthens the interaction participation among them. Therefore, this paper proposes the following hypothesis:

$\mathrm{H} 2$ : Trust has a positive effect on interaction participation.

\subsection{Information Environment}

As for information environment, this paper emphasizes the security of information environment. Security, including network security, information security, and users' 
Yi Peng and Yu-jie Li

security, means users' privacy and sensitive content in the virtual community are under protection. They are protected from various internal and external dangers, threats, harm, and misleading information. The security of information environment is a basic guarantee of interaction participation. In the process of interaction participation, users need to get protection in privacy, information, and systems. Interaction between users will not be effective and smooth if people fail to realize the above. Therefore, the following hypothesis is presented in this paper:

H3: Security has a positive effect on interaction participation.

\section{Methods}

\subsection{Measures}

We measured interaction participation with four items. The interaction participation scale is partly sourced from Lu [13]'s scale, and the other part sourced from Fan [6]'s scale. Responses were marked on a 5-point Likert scale ranging from $1=$ very inconsistent to 5 $=$ very consistent, and all items were reverse scored.

As for information factors, the usefulness scale (three items) was sourced from Cheung [3]'s scale. In terms of the factors of the information man, we measured trust (three items) using scales that were sourced from Gefen et al. [7], Luo [14], and Chiu et al. [4]. With respect to factors of information environment, the security scale (three items) was sourced from Wang et al. [24]'s scale.

In addition, gender, age, and level of education were used as control variables, following Hsu and Walter [9] and Seyedghorban et al. [21]. We also controlled for Internet experience and occupation. Since Internet experience has an impact on users' online behavior [18], their occupation might also influence their online behavior.

The first draft of the questionnaire was discussed multiple times by members of the research group; relevant experts were also consulted. A revised version is used for the formal survey.

\subsection{Sample}

Using a computer program, we randomly selected 2,580 users from among 2.6 million people in the sample bank of a professional online survey firm chosen by many Chinese research institutes and firms. We sent users an online questionnaire through email, push notifications, and other similar distribution methods. Before beginning the survey, participants were informed of the purpose of the study and method of data usage. They were then able to exit the survey if they were not willing to take part in this study. Four hundred and forty-nine surveys were returned (the return rate is $17.40 \%$ ) after a rejection of invalid responses (such as insufficiency in answer time, wrong keys in a trap question, obvious regularities in responses, and low frequencies in using a virtual community), and eventually 401 valid responses were collected (validity rate is $89.31 \%$ ). Of them, with 195 respondents, men account for $38.63 \%$, and with 206 respondents, women accounted for $51.37 \%$. In terms of age, there were 40 respondents in the age group of 19-25, accounting for $9.98 \%$; 285 respondents in the group of $26-35$, accounting for $71.07 \%$; 68 respondents in the group of 36-45, accounting for 16.96\%; and eight respondents above 45 , accounting for $2.00 \%$. Among all popular virtual communities, the usage rates of Baidu Tieba and Weibo were relatively high: $79.05 \%$ and $77.81 \%$, respectively. The usage rates of other common virtual communities, including QQCLUB, Tianya 


\section{Research on User's Interaction Participation in Virtual Communities Based on the Information Ecology Theory}

Community, Douban, and Zhihu were $47.88 \%, 46.63 \%, 36.91 \%$, and $34.41 \%$, respectively. Furthermore, $93.02 \%$ of the respondents had more than one year of experience in using virtual communities. As for the usage frequency, most respondents used them once a day, with a percentage of $52.37 \%$.

\section{Results}

We conducted a reliability analysis to confirm the scale's reliability, CFA to examine the rationality of the expected model, and multiple regression analysis to test the hypotheses.

\subsection{Reliability and validity}

Cronbach's $\alpha$ coefficient of the five variables (usefulness, trust, security, and interaction participation) can be calculated through SPSS 22.0, which is $0.618,0.701,0.765$ and 0.695 respectively. Hair, et al. [10] noted that, when the measure indices of variable are less than 6 , the scale is reliable on the premise of $\alpha>0.6$, while it is acceptable in exploratory researches even if $\alpha>0.5$. Therefore, the scale is equipped with relatively satisfying internal consistency reliability. Confirmatory Factor Analysis (CFA) results show that all the fit indexes are acceptable. The standard factor loading achieves comparatively high significance level $(\mathrm{p}<0.01)$, and manifests comparatively good convergent validity. The $95 \%$ confidence interval of the pairwise-related coefficients between factors does not contain 1 or -1 ; therefore, it has good discriminate validity.

There is a significant difference between the fitting result of Harman single-factor model and the fitting result of the five factors model, which implies that not all factors can be explained by one latent variable. Thus, common method variance bias is not serious.

In addition, variance inflation factors (VIF) of each variable in all of the models are far less than 10, which imply that there is no serious multicollinearity among variables, and the analysis result is reliable. Following the common method, we have used the mean value of scores gotten from the items' subordinating variables to represent the scores gained by variables.

Simultaneously, following the common method, we centralize the variables scores (subtracting the mean value of variables) to reduce the multicollinearity effect, before calculating interaction terms [1]. Table 1 shows the mean values, standard deviations, and correlation coefficients of variables.

Table 1: Mean, Standard Deviation and Correlation

\begin{tabular}{|c|c|c|c|c|}
\hline Variables & $\mathbf{1}$ & $\mathbf{2}$ & $\mathbf{3}$ & $\mathbf{4}$ \\
\hline 1. Interaction Participation & 1 & & & \\
\hline 2. Usefulness & $.582^{* *}$ & 1 & & \\
\hline 3. Trust & $.539 * *$ & $.577 * *$ & 1 & \\
\hline 4. Security & $.461 * *$ & $.400 * *$ & $.678^{* *}$ & 1 \\
\hline Mean Value & 3.953 & 3.910 & 3.497 & 3.395 \\
\hline Standard Deviation & .551 & .583 & .692 & .774 \\
\hline
\end{tabular}

Note. ${ }^{*} \mathrm{p}<0.05, * * \mathrm{p}<0.01$. 
Yi Peng and Yu-jie Li

\section{Hypothesis testing}

Usefulness has a positive impact on interaction participation $(\beta=0.376, p<0.01)$. Trust has a positive impact on interaction participation $(\beta=0.201, \mathrm{p}<0.01)$. Security has a positive impact on interaction participation $(\beta=0.184, \mathrm{p}<0.01)$. Thus, $\mathrm{H} 1, \mathrm{H} 2$, and $\mathrm{H} 3$ are supported. Table 2 presents the hypothesis testing, and the results are shown in Figure 1.

Table 2: Hypothesis Testing

\begin{tabular}{|c|c|c|c|}
\hline \multirow[t]{2}{*}{ Variables } & \multicolumn{3}{|c|}{$\begin{array}{c}\text { Dependent Variable: } \\
\text { Interaction Participation }\end{array}$} \\
\hline & Model 1 & Model 2 & Model 3 \\
\hline Age & -.048 & .005 & .003 \\
\hline $\begin{array}{c}\text { Education } \\
\text {-Bachelor Bellow }\end{array}$ & -.037 & -.023 & -.020 \\
\hline $\begin{array}{c}\text { Education } \\
\text {-Master or Above }\end{array}$ & -.012 & -.025 & -.024 \\
\hline $\begin{array}{c}\text { Occupation } \\
\text {-Education and Research } \\
\text { Development }\end{array}$ & -.058 & -.063 & -.063 \\
\hline $\begin{array}{c}\text { Occupation } \\
\text {-Institutional and Other Organizations }\end{array}$ & .054 & -.014 & -.014 \\
\hline Usefulness & & .398 & $.376^{* *}$ \\
\hline Trust & & .192 & $.201 * *$ \\
\hline Security & & .179 & $.184 * *$ \\
\hline $\mathrm{R}^{2}$ & .011 & .422 & .424 \\
\hline $\mathrm{F}$ & .861 & $35.741^{* *}$ & $26.053^{* *}$ \\
\hline$\Delta \mathrm{R}^{2}$ & .011 & .411 & .002 \\
\hline $\mathrm{F}$ of $\Delta \mathrm{R}^{2}$ & .861 & $92.874^{* * *}$ & .548 \\
\hline Maximum VIF Value & 1.058 & 2.347 & 2.460 \\
\hline
\end{tabular}

Note. ${ }^{*} \mathrm{p}<0.05, * * \mathrm{p}<0.01$.

\section{Conclusion}

Based on the information ecology theory, this paper built a research model in virtual communities. Using data collected through 401 surveys in virtual communities, we empirically tested the hypotheses. The main conclusion is that usefulness, trust, and security have positive impact directly on interaction participation. Therefore, users' interaction participation in the virtual community is affected by many aspects, including information, information man, and information environment. The better the information 


\section{Research on User's Interaction Participation in Virtual Communities Based on the Information Ecology Theory}

ecology that exists in a virtual community, the higher degree of users' interaction and participation will be.

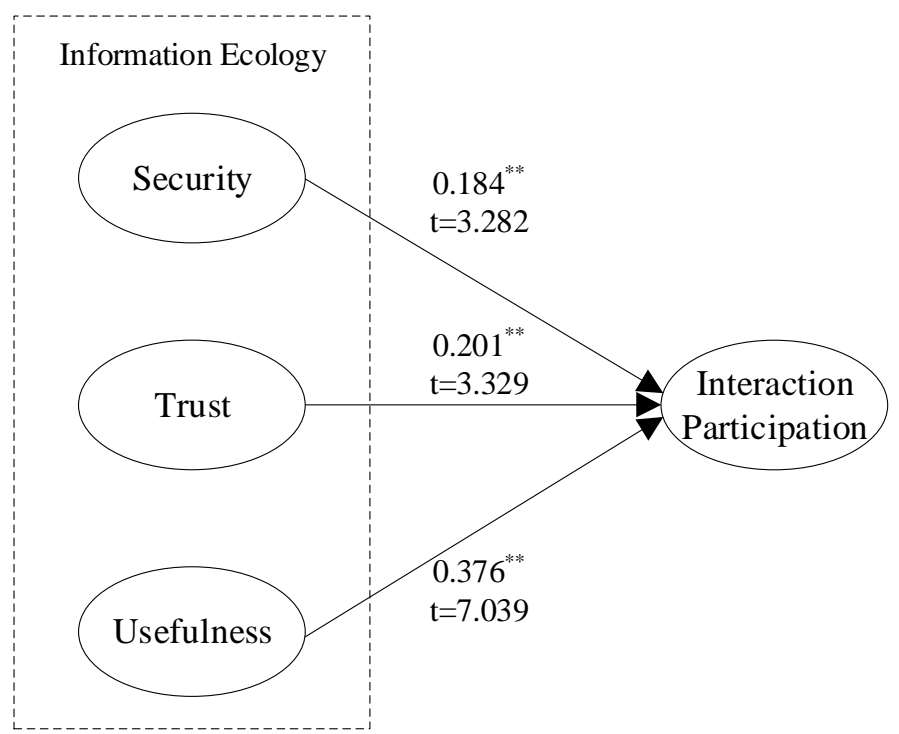

Figure 1: Research results

The theoretical significance provided in this research includes two aspects: On one hand, this paper focuses on virtual communities, and builds a research model of users' interaction participation. On the other hand, from the perspective of interaction participation, this paper analyzes interaction participation from three important elements which are information, information man and information environment. The empirical results indicate that the virtual community's managers should pay attention to users' interaction participation, which are influenced by many factors. In the process of their conducting architecture designs, function settings, and system improvements in the virtual community, there is a need to adjust relationships between the different factors, and to enforce the construction of the virtual community in order to support users' behaviors and promote the development of the virtual community.

Limitations of the study and future directions in this paper include: in the setting of the variable, there is a lack of consideration to information, information man, and information environment. To open and diverse virtual communities, these three main elements are influenced by many factors. This paper only selects the most important one as a variable from the factors influencing the three main elements, respectively.

Meanwhile, its measurement of the variable only reflects users' subjective willingness to participate and interact in virtual communities. Therefore, in future investigations, we could collect the data of users' real behaviors in virtual communities (for example, access numbers, reply numbers, collection numbers, etc.) to proceed with objective verification. Besides, because different types of virtual communities will have different influences on interaction and participation, future research may focus on one 
Yi Peng and Yu-jie Li

type of virtual community (such as a learning community, an interesting community, a transaction community, etc.) to carry out a targeted study on interaction participation.

Acknowledgements. This work is supported Chongqing University of Posts and Telecommunications Undergraduates' Scientific Research Training Program in 2015, "Information searching and knowledge sharing behavior of network users".

\section{REFERENCES}

1. L.S.Aiken and S.G.West, Multiple Regression: Testing and Interpreting Interaction, CA: Sage, Newbury Park, 1998.

2. S.Chen, Information ecological imbalance and balance, Information and Documentation Services, 4 (2002) 12-13.

3. R.Cheung, The influence of electronic word-of-mouth on information adoption in online customer communities, Global Economic Review, 43(1) (2014), 42-57.

4. C.M.Chiu and E.T.G.Wang, Understanding knowledge sharing in virtual communities: An integration of social capital and social cognitive theories, Decision Support Systems, 42 (2006) 1872-1887.

5. X.S.Chen and J.R.Yuan, Research of the information system elements of enterprise information resource ecological system, Technology Economics, 7 (2002) 21-22.

6. X.P.Fan, Virtual communities member's participating motive: An empirical study on non-trade virtual community in China, Journal of Industrial Engineering and Engineering Management, 23(1) (2009), 1-6.

7. D.Gefen, E.Karahanna and D.Straub, Trust and TAM in online shopping: An integrated model, MIS Quarterly, 27(1) (2003) 51-90.

8. M.H.Hsu, J.C.H.Yen and C.M.Chang, Knowledge sharing behavior in virtual communities: The relationship between trust, self-efficacy, and outcome expectations, International Journal of Human-Computer Studies, 65(2) (2007) 153169.

9. L.Hsu and Z.Walter, Search engine or content website? A local information seeking classification model based on consumer characteristics and website perceptions, International Journal of Human-Computer Interaction, 31 (2015) 263-276.

10. J.F.Hair, R.E.Anderson, R.L.Tatham and W.C.Black, Multivariate Data Analysis, Prentice Hall, New Jersey, 1998.

11. L.Q.Jiang, Information Ecology and Social Sustainable Development, Beijing Library Press, Beijing, 2003.

12. M.D.Li, The analysis of information ecology system, Journal of Information, 17(4) (1998), 3-5.

13. Y.F.Lu, Research on the Model of Interactive Communication in Virtual Community Effecting on Online Purchase Intention, Zhejiang University, Hangzhou, 2005.

14. S.X.Luo, Research of WOM Communication Effect on Purchase Decision: the Case of College Students, Zhejiang University, Hangzhou, 2007.

15. H.T.X.Mai and S.O.Olsen, Consumer participation in virtual communities: The role of personal values and personality, Journal of Marketing Communications, 21(2) (2015), 144-164.

16. T.Mayayisw and O.I.Olusegun, E-commerce assurance models and trustworthiness 
Research on User's Interaction Participation in Virtual Communities

Based on the Information Ecology Theory

issues: An empirical study, Journal of Information Management \& Computer Security, 22(1) (2014), 76-96.

17. B.A.Nardi and V.L.O'day, Information Ecologies: Using Technology with Heart, MIT Press, Cambridge, 1999.

18. R. Palanisamy, The impact of privacy concerns on trust, attitude and intention of using a search engine: An empirical analysis, International Journal of Electronic Business, 11 (2014) 274-296.

19. A.Schröder and K. Hölzle, Virtual communities for innovation: Influence factors and impact on company innovation, Creativity \& Innovation Management, 19(3) (2010) 257-268.

20. Y.C.Shen, C.Y.Huang and H.C.Liao, Virtual community loyalty: An interpersonalinteraction perspective, Informational Journal of Electronic Commerce, 15(1) (2010), 49-74.

21. Z. Seyedghorban, H.Tahernejad and M.J. Matanda. Reinquiry into advertising avoidance on the Internet: A conceptual replication and extension, Journal of Advertising, 45 (2016) 120-129.

22. X.W.Wang and D.Liu, Research of the elements and evaluation index construction of enterprise information ecological system. Library and Information Service, 54(16) (2010), 22-25.

23. X.W.Wang, M.Q.Yang and Y.F.Xing, Construction and empirical research of the ecological evaluation index for WAP portal: Analysis based on information ecology perspective, Information Studies: Theory \& Application, 38(6) (2015) 14-18.

24. X.W.Wang, M.Q.Yang, W.X.Zhang and Y.Guo, Evaluation of the ecology of the enterprise information portal: Analysis based on the perspective of customer experience, Library and Information Service, 58(4) (2014) 46-52.

25. W.S.Yoo, K.S.Suh and M.B.Lee, Exploring the factors enhancing member participation in virtual communities, Journal of Global Information Management, 10(3) (2002), 551-570.

26. Y.F.Yang, H.C.Yeh and W.K.Wong, The influence of social interaction on meaning construction in a virtual community, British Journal of Educational Technology, 41(2) (2010), 287-306.

27. L.Zhao, Y.B.Lu, P.Y.K.Chau and L.Zhang, Cultivating the sense of belonging and motivating user participation in virtual communities: A social capital perspective, International Journal of Information Management, 28(4) (2016), 15-32.

28. J.Zhang and R.A.Cohen, Framework for trust modeling in multiagent electronic marketplaces with buying advisors to consider varying seller behavior and the limiting of seller bids, ACM Trans on Intelligent Systems and Technology, 4(2) (2013) 1-33. 